\title{
The impact of e-commerce platform merchants' reputation on consumer decision making
}

\author{
Genghua Tang ${ }^{1}$, Lishan $\mathrm{Wu}^{2, *}$, Lei $\mathrm{Guo}^{3}$ \\ ${ }^{1,2 *}, 3$ School of Economics and Trade, Guangdong University of Technology, Guangzhou 510520, China
}

\begin{abstract}
By crawling Meituan take-out merchant data, this paper studies the influence of e-commerce platform merchants' reputation on consumer decision making. The empirical results show that the merchant reputation based on the overall score of merchants has a significant impact on consumers' purchase decision and then affects the monthly sales volume of merchants. At the same time, brand merchants have higher monthly sales than ordinary merchants, and a series of food safety guarantee measures such as food safety insurance purchase and food material publicity also significantly affect monthly sales. In addition, the overall score of platform merchants has a marginal diminishing effect on monthly sales. Based on the empirical research conclusions, this paper also puts forward relevant countermeasures and suggestions for Meituan platform merchants and government regulatory authorities.
\end{abstract}

\section{Introduction}

Virtualization and electronization of e-commerce transaction induce a series of new information asymmetry problems. It is difficult to identify the identity information of bilateral users and transaction-related information, and it is more difficult to control the moral hazard. The sustainable development of e-commerce is facing challenges. Under the condition of the continuous expansion of the transaction scale, it is still difficult to solve the problem of information asymmetry of the platform transaction fundamentally and effectively, whether it is external supervision in the form of public management or internal control in the form of selfrestraint. In the management practice of platform economy system, as an alternative signal display mechanism, the reputation mechanism based on buyer evaluation has increasingly become the main reference basis for consumption decision. Then, does the reputation mechanism have a substantial impact on the platform buyers' consumption decisions? At present, there are many descriptions and theoretical analyses of related phenomena, but empirical studies are still few. This paper attempts to capture the data of Meituan platform to study the influence of the reputation of online meal ordering platform merchants on consumers' decision-making, in order to provide reference for the further development of Internet platform economy.

\section{Research hypothesis}

In the existing literature, when studying the influence of platform merchants' reputation on merchants' sales volume, most of them choose total consumer score as an alternative indicator to measure merchants' reputation ${ }^{[1-2]}$. Positive comments can help other consumers make purchase decisions ${ }^{[3-4]}$, while negative comments can make consumers make decisions to avoid purchase ${ }^{[5-6]}$. It can be seen that consumer decisions can be reflected in the sales volume of merchants ${ }^{[7-8]}$.

Based on this, this paper proposes research hypothesis 1: the reputation of platform merchants has a positive impact on the sales volume of merchants.

In addition, price is also an important basis to measure the reputation of merchants, and to some extent, it can be used as a reference standard for consumers to evaluate the quality of goods. According to the demand function under equilibrium condition, when income is fixed, price is inversely proportional to sales volume. Therefore, price will affect consumer demand, that is, affect consumer decision, and further reflect the sales volume of merchants.

Therefore, this paper proposes research hypothesis 2: there is a negative correlation between platform merchant price and merchant sales volume.

It is worth noting that brand is also an effective signal to reflect product quality and has the function of identifying the goods and services offered by merchants and distinguishing them from competitors. Especially in the non-face to face e-commerce platform, brand merchants with platform certification have innate reputation advantage, and consumers are more inclined to choose the products of brand merchants.

Therefore, hypothesis 3 is proposed: the sales volume of brand merchants on the platform is higher than that of ordinary merchants.

As the subject of the transaction, platform merchants also take the initiative to take other measures to increase consumers' trust in them, such as purchasing insurance, publicizing raw materials for commodity production, and

\footnotetext{
* Corresponding author: 1016444900@qq.com
} 
becoming charity merchants. The main types of insurance to be purchased are freight insurance and food safety liability insurance. Merchants to provide freight insurance can provide consumers with more after-sales protection, easy to gain consumer favor. Food safety liability insurance and the disclosure of raw materials for commodity production can reflect the sanitary quality of the products of the merchants on the platform, so as to show the reputation of the merchants. Being a charity merchant means that every time a merchant completes an order, he or she will donate a certain amount of money to the special fund of the relevant charity plan. This is a manifestation of the platform merchants' active commitment to social responsibility, which can reflect the reputation of the merchant on the platform to a certain extent. Therefore, this paper further proposes the following research hypotheses:

Hypothesis 4: Platform merchants who purchase insurance sell more than ordinary merchants.

Hypothesis 5: Platform merchants that disclose raw materials for making goods sell more than ordinary merchants.

Hypothesis 6: The sales volume of charity merchants on the platform is higher than that of ordinary merchants.

\section{Model design}

This paper takes Meituan platform merchants as the research object, uses web crawler technology to directly capture the ordering data of four cities merchants in Beijing, Shanghai, Guangzhou and Shenzhen in November and December 2020, and uses empirical method to explore the influence of platform merchants' reputation on consumer decision-making. The research model is as follows:

$$
\begin{aligned}
\text { Sale }_{i t}=\beta_{0} & +\beta_{1} \text { Score }_{i t}+\beta_{2} \text { Consume }_{i t}+\beta_{3} \text { Price }_{i t} \\
& +\beta_{4} \text { Fee }_{i t}+\beta_{5} \text { Brand }_{i t}+\beta_{6} \text { Insurance }_{i t} \\
& +\beta_{7} \text { Public }_{i t}+\beta_{8} \text { Charity }_{i t}+v_{t}+u_{i}+\varepsilon_{i t}
\end{aligned}
$$

Among them, the meanings represented by each variable are shown in Table 1.

Table1. Variable meaning.

\begin{tabular}{|c|c|}
\hline Variable & Meaning \\
\hline Sale $_{i t}$ & $\begin{array}{c}\text { Monthly sales volume of merchant } i \text { at } \\
\text { time } t\end{array}$ \\
\hline Score $_{i t}$ & The overall score of merchant $i$ at time $t$ \\
\hline Consume $_{i t}$ & $\begin{array}{c}\text { The per capita consumption price of } \\
\text { merchant } i \text { at time } t\end{array}$ \\
\hline Price $_{i t}$ & $\begin{array}{c}\text { The initial delivery price of merchant } i \\
\text { at time } t\end{array}$ \\
\hline Fee $_{i t}$ & The delivery cost of merchant $i$ at time $t$ \\
\hline Brand $_{i t}$ & $\begin{array}{c}\text { Whether merchant } i \text { is a brand merchant } \\
\text { at time } t\end{array}$ \\
\hline Insurance $_{i t}$ & $\begin{array}{c}\text { Whether merchant } i \text { buys food safety } \\
\text { liability insurance at time } t\end{array}$ \\
\hline Publicit $_{i t}$ & $\begin{array}{c}\text { Whether merchant } i \text { publicizes food } \\
\text { materials at time } t\end{array}$ \\
\hline Charity & it \\
& $\begin{array}{c}\text { Whether merchant } i \text { is a public business } \\
\text { at time } t\end{array}$ \\
\hline
\end{tabular}

\begin{tabular}{|c|c|}
\hline $\mathrm{Vt}_{\mathrm{t}}$ & Time fixed effect \\
\hline $\mathrm{u}_{\mathrm{i}}$ & Merchant fixed effect \\
\hline
\end{tabular}

\section{Empirical analysis}

\subsection{Baseline regression analysis}

The estimation results of OLS and panel fixed effect model regression are shown in Table 2.

\begin{tabular}{|c|c|c|}
\hline & (1) & (2) \\
\hline Variable & OLS & FE \\
\hline Score & $35.753 * * *(41.615)$ & $36.423 * * *(36.166)$ \\
\hline Consume & $-0.150 * * *(-10.776)$ & $-0.138 * * *(-8.616)$ \\
\hline Price & $-0.166 * * *(-7.623)$ & $-0.153 * * *(-6.473)$ \\
\hline Fee & $-0.510 * * *(-12.654)$ & $-0.382 * * *(-7.443)$ \\
\hline Brand & $7.919 * * *(21.977)$ & $8.704 * * *(22.758)$ \\
\hline Insurance & $10.278^{* * *}(26.581)$ & $10.282 * * *(27.345)$ \\
\hline Public & $6.615 * * *(17.483)$ & $7.059 * * *(21.150)$ \\
\hline Charity & $17.049 * * *(36.914)$ & $16.675^{* * *}(28.571)$ \\
\hline cons & $\begin{array}{c}-143.287 * * * \\
(-35.558)\end{array}$ & $\begin{array}{c}-150.033 * * * \\
(-32.117)\end{array}$ \\
\hline $\mathrm{N}$ & 10825 & 10825 \\
\hline $\mathrm{R}^{2}$ & 0.448 & 0.457 \\
\hline Adjusted $\mathrm{R}^{2}$ & 0.448 & 0.456 \\
\hline $\mathrm{F}$ & 1097.840 & 508.908. \\
\hline
\end{tabular}

Table2. Estimated results of OLS and panel fixed effects model regression.

$$
\begin{aligned}
\text { Note: } & t \text { statistics in parentheses } \\
& { }^{*} p<0.1,{ }^{* *} p<0.05,{ }^{* * *} p<0.01
\end{aligned}
$$

Among them, column (1) is the impact of the overall rating estimated by the OLS benchmark model on the monthly sales of merchants, while column (2) is the impact of the overall rating estimated by the panel fixed effect model on the monthly sales of merchants.

First of all, it can be clearly seen from Table 1 that consumers' overall rating of merchants has a significant positive impact on the monthly sales of merchants. The specific statistical relationship can be quantified as that every $1 \%$ increase in the overall rating results in a $35.75 \%$ increase in the monthly sales of merchants, thus hypothesis 1 is verified.

Secondly, both OLS estimates and the coefficient results estimated by the panel fixed effect model show that the per capita consumer price, initial delivery price and delivery fee have a significant negative relationship with the monthly sales volume of merchants, so hypothesis 2 can also be confirmed. 
In addition, this paper introduced the brand merchants as a virtual variable, according to table 1 in two kinds of model estimation results show that the coefficient is significantly positive, indicating that there is brand chasing effect when consumers make consumption choices. Compared with ordinary merchants, consumers have an impression on brand merchants, so they are more likely to be favored by consumers. Therefore, hypothesis 3 is confirmed.

Besides, the food security liability insurance, the public of ingredients is also introduced as virtual variables in this paper. According to the estimated results, both the purchase of food safety liability insurance and the publicity of food materials by the platform merchants have a significant incentive effect on consumers to purchase their products. This is because the products sold on Meituan platform are mainly food, and Meituan merchants should also ensure the safety of consumers while providing food. Therefore, whether a merchant buys food safety liability insurance and publicizes food ingredients can significantly affect consumers' consumption decisions on the products of the merchant, thus hypothesis 4 and 5 are verified.

Finally, this paper also introduced charity merchants as the virtual variable. In the Meituan platform, some merchants participated in the 'Qingshan Charity' program and became the charity merchants of Meituan platform. The empirical results show that Meituan merchants' performance of 'Qingshan charity' program has a significant positive correlation with the monthly sales volume of merchants, which indicates that whether a merchant performs social responsibility is also an important part of a merchant's reputation. Consumers tend to prefer merchants that perform social responsibility, so hypothesis 6 is confirmed.

\subsection{Piecewise regression result}

This paper divides the overall score of Meituan merchants in four cities into four sections: $(3,3.5],(3.5,4],(4,4.5]$, and $(4.5,5]$. Then sets four virtual variables to indicate whether the overall score of merchants falls within these four sections respectively. Finally, this paper makes a regression estimate of the impact of the overall score of merchants among partitions on the monthly sales of merchants, and the results are shown in Table 3.

As can be seen from Table 3, the influence range of the overall score of merchants on the Meituan platform on the monthly sales of merchants shows a trend of increasing at first and then decreasing, that is, the coefficient value of the overall score among different partitions, increases at first and then decreases. When the score range of the merchants falls in the section $(3,4)$, the overall score has a significant positive impact on the monthly sales of the merchants, and the driving extent of the overall score on the monthly sales of the merchants is gradually increasing. When the score range of the merchants falls in the section $(4,5)$, the overall score still has a significant positive impact on the monthly sales of the merchants, but the increase rate is lower than that of the merchants in $(3,4)$.
This result shows that when the overall score of a merchant is above 4, the score level is not the only reference for consumers to make decisions, and consumers may attach more importance to other factors such as the brand of the merchant and food safety. In addition, it can not be ruled out that when the merchant's score is too high. It will face with the questions of cheating to get high points, which will lead to the negative signal to the consumer decision making.

Table3. Regression estimation results of the effect of overall score between partitions on monthly sales of merchants.

\begin{tabular}{|c|c|c|c|c|}
\hline Variable & $(3,3.5]$ & $(3.5,4]$ & $(4,4.5]$ & $(4.5,5]$ \\
\hline Score & $\begin{array}{c}38.708 \\
* * * \\
(47.920) \\
\end{array}$ & $\begin{array}{c}41.205 \\
* * * \\
(47.821) \\
\end{array}$ & $\begin{array}{c}27.448 \\
* * * \\
(25.989) \\
\end{array}$ & $\begin{array}{c}26.106 \\
* * * \\
(21.098) \\
\end{array}$ \\
\hline Consume & $\begin{array}{c}-0.127 \\
* * * \\
(-10.038)\end{array}$ & $\begin{array}{c}-0.129 \\
* * * \\
(-10.168) \\
\end{array}$ & $\begin{array}{c}-0.124 \\
* * * \\
(-9.849)\end{array}$ & $\begin{array}{c}-0.124 \\
* * * \\
(-9.820)\end{array}$ \\
\hline Price & $\begin{array}{c}-0.155 \\
* * * \\
(-7.813)\end{array}$ & $\begin{array}{c}-0.155 \\
* * * \\
(-7.838)\end{array}$ & $\begin{array}{c}-0.156 \\
* * * \\
(-7.944)\end{array}$ & $\begin{array}{c}-0.156 \\
* * * \\
(-7.911)\end{array}$ \\
\hline Fee & $\begin{array}{c}-0.427 \\
* * * \\
(-11.581)\end{array}$ & $\begin{array}{c}-0.436 \\
* * * \\
(-11.854)\end{array}$ & $\begin{array}{c}-0.437 \\
* * * \\
(-11.924)\end{array}$ & $\begin{array}{c}-0.435 \\
* * * \\
(-11.855)\end{array}$ \\
\hline Brand & $\begin{array}{c}7.822 \\
* * * \\
(23.838) \\
\end{array}$ & $\begin{array}{c}7.901 \\
* * * \\
(24.144)\end{array}$ & $\begin{array}{c}7.936 \\
* * * \\
(24.345) \\
\end{array}$ & $\begin{array}{c}7.916 \\
* * * \\
(24.219)\end{array}$ \\
\hline Insurance & $\begin{array}{c}10.087 \\
* * * \\
(28.654)\end{array}$ & $\begin{array}{c}10.162 \\
* * * \\
(28.943)\end{array}$ & $\begin{array}{c}10.194 \\
* * * \\
(29.146)\end{array}$ & $\begin{array}{c}10.160 \\
* * * \\
(28.975)\end{array}$ \\
\hline Public & $\begin{array}{c}6.574 \\
* * * \\
(19.086)\end{array}$ & $\begin{array}{c}6.668 \\
* * * \\
(19.403)\end{array}$ & $\begin{array}{c}6.725 \\
* * * \\
(19.645)\end{array}$ & $\begin{array}{c}6.673 \\
* * * \\
(19.445)\end{array}$ \\
\hline Charity & $\begin{array}{c}17.096 \\
* * * \\
(40.651)\end{array}$ & $\begin{array}{c}17.053 \\
* * * \\
(40.664)\end{array}$ & $\begin{array}{c}17.053 \\
* * * \\
(40.824)\end{array}$ & $\begin{array}{c}17.059 \\
* * * \\
(40.730)\end{array}$ \\
\hline $\mathrm{N}$ & 10825 & 10825 & 10825 & 10825 \\
\hline$\overline{\mathrm{R}^{2}}$ & 0.505 & 0.507 & 0.511 & 0.509 \\
\hline $\begin{array}{c}\text { Adjusted } \\
\mathrm{R}^{2}\end{array}$ & 0.504 & 0.507 & 0.511 & 0.508 \\
\hline $\mathrm{F}$ & 1101.729 & 1114.185 & 1131.407 & 1119.646 \\
\hline
\end{tabular}

\section{Conclusions and Suggestions}

This paper uses web crawler to capture the merchant data of Meituan takeout platform in November and December 2020.The overall score of merchants is taken as the index of merchants' reputation, and the monthly sales volume of merchants is taken as the index of consumers' decisionmaking. Through studying the influence of overall score of merchants on monthly sales volume of merchants, the influence of platform merchants' reputation on consumers' decision-making is studied. The empirical results show that there is a significant positive correlation between merchants' overall score and their monthly sales, that is, merchants' reputation on the platform in the form of merchants' overall score can promote consumers' purchase decisions to a certain extent and thus affect merchants' sales. The per capita consumer price, initial delivery price and delivery cost are significantly negatively correlated with the monthly sales. In addition, whether the platform merchants are brand merchants, whether they buy 
insurance, whether they disclose raw materials for commodity production, and whether they participate in public welfare activities all significantly affect consumers' decisions. Therefore, the brand of merchants and their product safety and quality assurance measures constitute the complementary reputation of merchants on the platform and can also have an impact on their monthly sales volume. Finally, through the regression results of the overall score among 4 sections, it is concluded that the impact of the overall score of the merchants for the monthly sales of the merchants on the Meituan platform has interval differences, and the overall impact range shows an increasing trend at first and then decreasing trend.

Based on the above research conclusions, this paper puts forward the following suggestions for the platform, the platform merchants and the government regulatory authorities.

Firstly, the platform as the main body of manage and control the reputation mechanisms should continuously optimize and improve the platform reputation mechanism in view of the problem existing in its actual operation. It is necessary for the platform to further optimize the evaluation and rating system by strengthening technical control and institutional constraints, give full play to the leading and core role of the platform in the construction and cultivation of the platform reputation mechanism, solving the problems of false evaluation caused by the imperfect scoring system, and ensure the effectiveness and reliability of the reputation mechanism.

Secondly, as the evaluation objects and participants of the reputation mechanism, the platform merchants should not only win consumers' recognition through standardized and compliant operation, but also win consumers' favor by purchasing food safety liability insurance, the public of food material, regular self-inspection of the sanitary conditions of the business premises, and actively participating in public welfare activities. At the same time, platform merchants should actively participate in the evaluation and rating of the transaction process through various ways and cooperate with the platform to jointly build the reputation mechanism of the platform and create a healthy platform ecosystem.

Thirdly, the government and other relevant public administrative institutions act as the external regulatory subjects of the platform economy system. On the one hand, they should strongly support the construction and cultivation of the platform reputation mechanism. On the other hand, they should establish credit files of merchants outside the platform score rating system, those who independently take food security measures, conduct selfinspection and publicity, participate in public welfare activities into the high-credit merchants, regularly check their credit changes. In addition to the platform's own score, it provides more adequate official certification information for buyers to make purchase decisions.

\section{Acknowledgments}

The authors acknowledge the support from the National Social Science Foundation of China under Grant No. 20BGL097.

\section{References}

1. Goes, P. B., M. Lin, and C. A. Yeung. Popularity Effect in User-generated content: Evidence from Online Product Reviews [J]. Information Systems Research ,2014,25(2) :222-238.

2. $\mathrm{Hu}, \mathrm{N}$., P. A. Pavlou, and J. Zhang.On Self-Selection Biases in Online Product Reviews[J]. MIS Quarterly,2017, 41(2): 449-471.

3. Chintagunta, P.K., Gopinath, S., and Venkataraman, S. The effects of online user reviews on movie box office performance: Accounting for sequential rollout and aggregation across local markets[J]. Marketing Science,2010, 29(5): 944-957.

4. Cheung, C. M. K., and Lee, M. K. O. What drives consumers to spread electronic word of mouth in online consumer-opinion platforms $[\mathrm{J}]$. Decision Support Systems, 2012,53(1):218-225.

5. Wang F., Liu X. F, Fang E. User Reviews Variance, Critic Reviews Variance and Product Sales: An Exploration of Customer Breadth and Depth Effects [J] . Journal of Retailing,2015,91(3): 372-389.

6. Dong, H. L. An Alternative Explanation of Consumer Product Returns from the Post-purchase Dissonance and Ecological Marketing Perspectives [J] .Psychology and Marketing,2015,32(1): 49-64.

7. Dimoka, A., Y. Hong, and P. A. Pavlou. On Product Uncertainty in Online Markets: Theory and Evidence[J]. MIS Quarterly,2012,36(2):395-426.

8. Hong, Y. (Kevin) and P. A. Pavlou. Product Fit Uncertainty in Online Markets: Nature, Effects, and Antecedents[J]. Information Systems Research 2014,25(2):328-344. 